move the limbs, and, in fact, is unable to do so, and they lie helpless in an everted position on the bed, presenting a condition of psendo-paralysis similar to that which we noted as being present in the syphilitic form of the disease. The general trentment of this condition consists in the adminis. tration of some fresh raw vegetalule-of which, perhaps, orange juice is the best-with raw meat juice and milk and plenty of fresh air. The local treatment consists in fixation and perfect rest of the affected limbs, for it must be borne in mind that the blood extravasation is the primary lesion, and that the subsequent fracture probably arises from some slight degree of violence acting on the weakened bone, and therefore every care should be taken by fixing the swollen limbs to prevent this accident taking place. Even after fracture has occurred fixation is still necessary in order to keep the broken ends in apposition and promote uuion, which in cases that recover seems to take place readily and rapidly and, if attention is paid to position, without deformity. The affected limbs should be bandaged with soft flannelette bandages in such a way as to fix them in a straight and extended position, and the child should be laid on a soft pillow, to which it can be fixed by a broad flannel bandage pissed over the trunk, and on which it can be carried about and even taken into the open air with as little movement to the child's limbs as possible. Sometimes wet compresses seem to give the child relief, but the objection to them is that they require coastantly renewing, and this exposes the infant to constant movement, which is prejudicial to its recovery. The disease is often fatal in spite of treatment, but in the cases which do recover it is astonishing to see the rapidity with which improvement takes place on a plan of treatment based on these lines.

In conclusion, I desire to record the notes of one case which fell under my care, certainly the worst case which I have seen, and in which the result of the treatment was most satisfactory. An infant aged nine months was admitted into the Victoria Hospital for Children, uvder my care, on Nov. 2nd, 1891. It was stated that the motber had died at the birth of the child, and that consequentiy the child had been brought up by hand; but no definite history could be obtained as to what kind of food had been given. The only fact that could be elicited was that it had had "milk or anything." It had always been a weak and sickly child, and had at one time been under treatment as an out-patient for general debility. The swelling of the scalp and shoulders, from which it suffered when admitted, was attributed by the woman who brought it up to a fall on the floor from its nurse's arms. When admitted the child was found to be in a miserably emaciated condition, with extreme pallor of the skin and mucous surfaces. It lay on the bed, making a constant low whining noise, and cried out at once upon any attempt being made to touch or move it. There was general œdema of the scalp, with three distinct points of fluctuation, one in front of and above the left ear, another over the right temple, and a third just below and to the right of the occipital protuberance. There was swelling in the neighbourhood of both shoulder-joints and also of the left knee-joint, and in both upper ends of the humeri and in the lower end of the left femur there was increased mobility in the continuity of the bore upon making lateral movement, and distinct grating or crepitus could be felt. The child made no attempt to move these limbs, which were in a condition of pseudo-paralysis. Upon examining more closely there was found to be thickening along the whole length of the right humerus and the left femur, but in the left humerus the thickening was confined to the upper end of the bone. In the front of the right knee-joint just to the outer side of the patella was a large extravasation of blood of a purplishblack colour and a similar one on the back over the lower dorsal and upper lumbar spines. There was no fetor of the breath, nor were the gums spongy. The pulse was very feeble, and the abdomen distended. The child was ordered raw meat juice, milk, and fresh orange juice, and the limbs were bandaged to fix them. On Nov. 10th, in ten days' time, there was a marked change in the child. It was bright and lively, and took its food and slept well. The fluctuating swellings over the scalp had nearly disappeared. The swelling of the limbs was much less. The child continued to improve ; the swellings gradually disappeared; it again began to move its arms and legs. The grating of the ends of the bones could no longer be felt, and the child was discharged on Dec. 5th-that is to say, on the thirty-third day after admission-perfectly well.

\section{ON RECURRENT APPENDICITIS OR RE CURRING APPENDICULAR COLIC, WITH CASES TREATED BY OPERATION IN THE QUIESCENT PERIOD. ${ }^{1}$}

BY A. W. MAYO ROBSON, F.R.C.S. ENG., L.R.C.P. LOND。, HON. SURGEON, GENERAL INITRMARY AT LFEDS ; PROFESSOR OF SURGEKY, VICTORIA UNIVERSITY ; MEMBER OF COUNCIL OF THE ROYAL COLLEGE OF SURGEONS OF ENGLAND.

THERE is perhaps no subject of greater interest to both physician and surgeon, or presenting greater difficulty in deciding on the appropriate line of treatment to be pursuew in each individual case, than that of inflammation starting in the neighbourhood of the cæcum and for so long known as typhlitis or perityphlitis, but which more recent researches have told us is practically always dependent on appendicitis in one or other of its forms. If time would permit, it would be interesting to discuss the whole subject and to give cases illustrating the different varieties of the disease and the various complications to which they may give rise, but this would probably be less profitable in discussion than to limit my remarks, or, at all events, the record of cases, to thoso known as recurrent appendicitis or to recurring appendicular colic, the latter term being applied to the cases, like Cases 3 and 4, where some of the seizures were often of short duration and evidently not always accompanied by peritonitis. I wish to be quite clear, in the first place as to what is meant by appendicitis; and to understand this it may not be unprofitable to consider the appendix vermiformis as a thick bollow tube of adenoid tissue resembling the tonsils in structure, lined on its inner surface by a layer of epithelium, and covered on its outer by a muscular tube and a peritoneal investment. The continuity of the tube with the intestine, always containing septic material; the thin layer of epithelium alone, guarding the tonsil-like tissue from infection; the narrow lumen of the tube, easily blocked by the swollen lymphoid tissue; the muscular layer, readily excited to severe and painfal spasm. and the thin peritoneal investment, part of the general peri: toneal cavity-constitute an anatomical series which may not unaptly be termed a veritable death trap, when from an local cause, whether in the shape of injury or disease, the protecting epithelium becomes displaced, allowing bacterial invasion of the lymphoid tissue and producing an infective inflammation which is known as "appendicitis," which may be acute, subacute, or chronic, the last-mentioned being the form that usually furnishes the cases of recurrent appendicitis. This infective appendical inflammation may pursue one of several courses, or several courses together, and among these the following may be mentioned :1. Local adhesive peritonitis by direct irritation of the peritoneal envelope, leading to adhesions of the appendis to neighbouring parts. 2. Abscess, either subperitoneal, dus to lymphatic infection, or within the tube, due to ulceration of mucous membrane, the lumen of the tube having becoms blocked. The abscess, once formed, may burrow between the layers of the mesentery of the tabe, forming an extraperitoneal abscess; or if poured out through the peritoneal coat of the appendix it may be limited by the adhesion of neighbouring coils of intestine, or may burst into contiguous viscera if adhesions bave occurred, producing cystitis, nephritis, \&c., according to its course, or may lead to a chronic septicæmia; or it may rupture. into the general peritoneal cavity, producing perforative general peritonitis. 3. Inflammation may extend along the lymph channels to the cæeum, producing a true typhlitis or perityphlitis, which may or may not end in suppuration. 4. Infectious thrombosis of the vessels-if of the single artery, leading to gangrene of the appendix and acute peritonitis; if of the veins, leading to septicæmia os pyæmia, or possibly to abscess of the liver. 5. General peritonitis by direct extension without perforation, producing paralysis of bowel and symptoms of acute intestinal obstruction. 6. Violent colic, due to the irritation of the muscular coat and its violent contractions to try to force the contents of the tube, whether fæcal or othen

1 A paper read before the Leeds and West Riding Medico-Chirurgicas A paper read before the
Socty on Nov. 3rd, 1898 
concretion, or pus or mucus, through the contracted orifice into the cæcum. 7. Stricture, due to the healing of an ulcer and accumalation of mucus in the distal end of the tube, producing periodical attacks of colic.

The following cases will serve to illustrate the recurrent form of appendicitis and its treatment by operation.

CASE 1. -This case, which was diagnosed by Dr. Wardrop Griffith and operated upon on Jan. 19th, 1892, after seven severe and numerous slighter attacks, was found to be due to an appendix strictured a quarter of an inch from the cæcum, the distal portion being distended with muco-pus. The case was reported in THE LANCET in 1892. The patient has had no repetition of her attacks.

CASE 2.-A married woman aged twenty-seven was operated upon on Nov. 5th, 1892, on account of repeated attacks of pain in the crcal region, at times accompanied by swelling, and, when the attacks were severe, always accompanied by distension of the abdomen and constipation. The patient dated the onset of her illness to a fall four and a half years previously, which produced a miscarriage and was followed by dysmenorrhœa and other pelvic symptoms, for which operative measures had been adopted two years and fifteen months previously, but although her pelvic symptoms were cured the distress in the cæcal region was no better, and she was quite unable to perform her domestic duties, as the slightest exertion brought on the pain and she was always conscions of discomfort between the severer seizures. On admission to the infirmary pressure with the finger on a spot two inches internally to the right anterior superior spine of the ilium produced severe pain, and here could be felt a swelling with induration. The creal region was explored through an oblique incision of three inches at the lower end of the right linea semilunaris, and the appendix was found on the inner side of the crcum, bound down by omental and intestinal adhesions. It was removed close to the cæcum, as it was found to be swollen and rigid throughout, and within it could be felt two hard masses. After removal it was found to contain muco-pus and two hard fæcal concretions. Recovery was aninterrupted, and when last seen the patient expressed herself as well and as having had no return of her symptoms.

CASE 3.-A man aged thirty-one was seen in February, 1892 , in consultation with Mr. Wright of Stamford Bridge. The history dated from November, 1889, when the patient suffered from fever and pain in the cæcal region, which was so slight that no medical man was consulted and he only remained in bed for two days. The next attack occurred in January, 1890, and the medical man who saw him pronounced it to be inflammation of the cæcum. From that time numerous attacks-twenty or more-had occurred, some of short duration, others longer and more serious. Some of the attacks had been followed by jaundice, but there had never been pain in the right shoulder, and the pain had always started low down on the right side of the abdomen. When I saw him he was just recovering from an attack which had commenced ten days before; there was then tenderness over the cæcum, with some swelling. McBurney's sign was well marked, but rectal examination was negative. There was no tenderness or swelling over the liver or gall-bladder. Operation was advised, and on March 4th, 1892, an inflamed and adherent appendix was removed with considerable difficulty on account of the firmness of the adhesions and the extensive separations that had to be effected before the appendix could be reached behind and to the inner side of the cæcum. Convalescence was somewhat delayed by thrombosis in the right femoral vein; otherwise there was nothing to chronicle. In May be came to see me, looking and feeling well. I have since heard that there has been no repetition of the attacks, and that the patient keeps well.

CASE 4.-A man aged twenty-three was seen in association with Dr. Oliver of Newcastle, who diagnosed the case as one of appendicitis. The patient had typhoid fever in August, 1884, but had no further trouble until June, 1885, when he had some pain in the right side of the abdomen, said to be dne to "gravel" by a French practitioner. His first distinct attack was on June 6th, 1890, when he was said to have inflammation of the bowels and was seriously ill. The attacks were repeated in February, May, June, and July, when a medical man found a swelling in the cæcal region for the first time. Three attacks occurred between July and November, when he saw Dr. Oliver, and after that a London surgeon, who said there was thickening over the large bowel and advised rest and massage. In March, 1891, he had another seizure and saw the same surgeon again, wbo did not advise operation. The attacks recurred in May, July, and September, 1891, and then not again till May, 1892, after which he had several seizures before seeing me on July 16th, 1892, when I found a swelling in the cæcal region the size and shape of a small sausage, and tender on pressure, especially at a point two inches to the inner side of the anterior superior spine of the ilium and between it and the umbilicus. The tumour was smooth, slightly movable, and did not pit on pressure. It could not be felt through the rectum, He told me that after an attack he frequently noticed pus in the motions. I advised operation, which was performed on Sept. 2, 1892, Dr. Oliver being present. The appendix was discovered in the midst of adhesions, behind the cæcum, but was easily isolated. It was strictured a short distance from the creum, and the distal extremity was dilated into a sansage-shaped cyst containing muco-pus. Recovery was uninterrupted, and the patient returned home within the month. I have not seen him since, but have had a report this year telling me that he is in good bealth and bas had no repetition of his old trouble.

CASE 5.-A lad aged thirteen was operated on during his third attack of appendicitis, as when I saw him with $\mathrm{Mr}$. Scarth the symptoms were thought to be too acute for delay. The first seizure occurred in June, 1893, when he was in bed a fortnight, and the second in August. Each time be had pain across the abdomen and in the cæcal region, nausea vomiting, and fever, and in the first attack there was much distension. The third illness commenced during the night of Jan. 17th, after eating a heavy supper, when he was suddenly attacked with pain in the right iliac region, nausea, and vomiting. Opium was given and hot fomentations were applied without relief. Distension supervening on the third day, a consultation was held, and the patient was sent to the infirmary. When admitted on the evening of Jan. 2lst he lay on his back with his knees drawn np, and looked extremely ill ; his face was pinched, and expression anxious. pulse rapid, small and feeble; breathing quick; temperature $101.5^{\circ} \mathrm{F}$; ; tongue dry and furred. He was vomiting dark-green fluid. The abdomen was very much distended and tender, especially in the right iliac region where the pain was severe. A turpentine enema was given and the bowels were freely moved, giving some relief. On the morning after his admission the peritoneal cavity was opened, and a little clear fluid escaped. The intestines were congested. After separating adhesions the appendix, which was about two inches in length and much thickened and coated with lymph, was found passing from the back of the cæcum over the brim of the pelvis. It was ligatured and removed close to its orgin, and the peritoncum was separately sutured over the stump. When the appendix was squeezed immediately after its removal, several drops of creamy pus oozed from a minute hole in the dilated end of the tube, and when laid open the cavity was found to contain pus and débris, but no concretion. The cæcal region was carefully cleansed, after which a rubber drain was inserted over the brim of the pelvis. The drainage-tube was removed in thirty-six hours, and the sutures on the seventh day. The patient made a good recovery, was up sixteen days after the operation, and went home in the third week. He has had no farther discomfor and is now quite well.

CASE 6.-A young man aged twenty-three was seen by me in consultation with Dr. Hector of Drighlington on Jan. 22nd, 1897, just recovering from an acute attack of appendicitis. A sausage-shaped tumour could be felt in the cæcal region, which was still tender on pressure. The patient had had three similar attacks within six months. He was sent to the infirmary, and on Jan. 25th after opening the abdomen numerous intestinal adhesions were separated, and the appendix, which was found behind the distended crecum, was swollen to the thickness of a thermometer case and very firm and rigid. It was ligatured at its base and removed the wound being closed by peritoneal, muscle, and integamental sutures separately. Recovery was uninterrupted, and the patient went home on Feb. 17th. He is now quite well.

CASE 7.-A married woman aged thirty-seven was sent̂, by Mr. Anderton of Southport, who said that during the last two years the patient had had eleven attacks of appendicitia, the more recent seizures having been more severe and at shorter intervals. Her last attack, in December, 1893, had kept her in bed three weeks. She was seen by me soon after this attack, when the usual tender spot was found, together 
with an ill-defined swelling in the cacal region, and operation was advised. On admission on Jan. 30th the patient was in very fair condition, and the tumour was much less distinct. The pain and tenderness had also disappeared. The abdomen was opened on Feb. 1st, and after adhesions had been separated the swollen appendix was discovered behind the cxcum, harder and firmer than usual. It was ligatured at its base and removed, the peritoneal covering being sutured separately over it. On laying it open after removal, muco-pus escaped, and the mucous membrane was found thickened and congested. The lumen was much diminished at its cæcal extremity, but a small probe could be passed. No drainage was employed, and the layers of the abdominal wall were sutured septrately. The patient made an uninterrupted revovery aud left the hospital on Feb. 24th looking very well.

CAS3 8.- A man aged thirty, a patient of Mr. Lambert of Farsley, was seen by me in January, 1894, recovering from an attack of inflammation in the cæcal region; a tumour about the size of a small pear could be felt, and there was marked tenderness. He had had six similar attacks during the two previous years, and in each seizure his medical attendant had been able to feel the tumour. The attacks had been increasing in severity, and the last had kept him in bed a fortnight. On admission on Feb. 5th, a month after the last seizure, he was in fair general health, and no lump could be felt, although there was some tenderness at McBurney's point. On the 15th, when the abdomen was opened, there was great difficulty in finding the appendix, on account of extensive and firm intestinal adhesions in the crcal region. It was at last found buried in a thick layer of old adhesions behind the cæcum. When separated it was found to be small and doubled back on itself. After removal a stricture was discovered at its cæcal extremity, which only admitted the very finest probe. The distal end was dilated and contained a little yellowish clear mucus. Its coats were thickened, and the mucous membrane was congested. No drainage was employed. The wound healed by first intention, and recovery was uninterrupted. The patient is now at his work and has had no return of pain.

CASE 9.--A married woman aged twenty-five was sent to me by Dr. Howell of Middlesbro' with the history of having been ill more or less for seven years, during which period she had suffered frequently from attacks of pain in the abdomen. Her most severe seizure had occurred five months previously, and she said this had started just as her previous attacks had done, but on this occasion Dr. Howell discovered a swelling in the region of the cæcum. She was in bed nine weeks, but soon after getting about again another attack occurred, and the tumour was again perceptible. Her general health had failed seriously, and she was very thin and ill-looking. When we saw her together there was a decided fulness and tenderness over the cæcum, McBurney's point being well marked. Recurrent appendicitis was diagnosed, and the patient was operated upon on Feb. 22nd, Dr. Howell assisting me. Namerous adhesions were discovered, and with difficulty a diseased appendix was removed from behind the cæcum. The wound healed by first intention, and although the patient developed a small patch of pneumonia within a week of the operation-apparently dependent on a chill received on the journey to Leeds-she made a good recovery and was able to return home within the month.

I have operated on other cases where recurrent appendicitis has gone on to perforation or abscess, but I prefer to limit my remarks to the characteristic ones related, where the operation was performed between the attacks. In such cases there are clearly three courses which may be pursued :1. Non-operative, trusting to rest and diet, with opium if required, in order to bring about resolution in the hope that the existing attack may be the last. 2. Operation on the second or tnird day of a seizure as advised by Dr. F. S. Dennis and other American surgeons who discourage the removal of the appendix between the attacks on the chance that there may be no recurrence. 3 . Operation in the quiescent period, between the attacks. My practice will show that I decidedly prefer to operate in the quiescent period if opportunity be given to choose the time - (1) because the patient is likely to be in the best possible condition; (2) because there is less likelihood of there being an extensive collection of inflammatory products in or in the neighbourhood of the appendix. and therefore there will be less danger of soiling the general peritoneal cavity and less fear of peritonitis ; (3) an operation in the quiescent period seldom requires drainage, and therefore the wound can be made secure, and there will be less likelihood of hernia following operation; and (4) the appendix can be dealt with in a more satisfactory manner than when it is acutely inflamed and hidden by greatly distended intestines. In deciding on the line of treatment, $q u \hat{a}$ medical or surgical, the patient should have matters fully explained to him, the dangers of recurring attacks, with the sufferings and inconveniences, being balanced against the risk of operative interference and the result, gained by operation; therefore, in all these cases I would urge the coöperation of physician and surgeon, so that, if possible, the opinion given may be free from bias. Can these several risks be estimated? Fitz gives the mortality of perityphlitis medically treated as 11 per cent.; this is probably too high for attacks of recurrent appendicitis, but who is to say that in any case the next seizure may not end in perforation and death? What are the inconveniences? In all the cases related, incapacity for the ordinary pursuits of life and practically chronic invalidism were marked features. What is the likelihood of recurrence? In the cases related there seemed to be every probability of the recurrences being repeated indefinitely, and I should say that if in any case the attacks were repeated two or three times they would not unlikely recur many more times until some complication supervened.

What are the risks of operation in the quiescent period? Here we stand on more certain ground, for published statistics prove the dangers to be very slight in the hands of those accustomed to such operations-I -I believe not more than 2 or 3 per cent. And, lastly, What are the results which may be looked forward to after recovery from operation? In such cases as have been reported, and in my own now mentioned, the patients have been apparently completely cured.

Although I do not agree with those surgeons who argue that every case of appendicitis should be operated on, I do feel that in recurrent appendicitis operation shonld be resorted to as soon as it becomes evident that there is a probability of the attack being repeated, especially as the operation is one that can be undertaken in the quiescent period with every prospect of immediate and ultimate success.

For the notes of Cases 5, 6, 7, and $8 \mathrm{I}$ have to thank my house surgeon, Mr. C. H. Oldfield.

Leeds.

\section{NOTE ON DIARRHEA AND ITS RELATION TO FRUIT AND THE FEEDING BOTTLE. ${ }^{1}$}

By J. SPOTTISWOODE CAMERON, M.D., B.Sc. EdiN., CONSULTING PHYSICIAN TO THE HUDDERSYIELD INFIRMARY, MEDICAL OFFICER OF HEALTH FOR LEEDS, ETC.

LAST autumn the annual death - rate from autumnal diarrhœa was 3.5 per 1000 in the 33 great towns, 3.8 in 50 large town districts, and in England and Wales (less these 83 towns) 2:1. Last autumn was, however, a period of unusually high mortality from this cause. The diarrhoal death-rate had been 40 per cent. above the autumn average of the ten preceding years in the 33 towns, 123 per cent. above in the 50 town districts, and 110 per cent. in the rest of England and Wales. Many districts, especially in Lancashire and Yorkshire, with a usually high rate from this cause, had a smaller proportionate increase last autumn than others with an ordinarily lower rate. Thus, amongst the large towns Leeds, with a decade rate of 3.4 , ran up 50 per cent., to $5 \cdot 1$; while Bradford, with a decade record of $2 \cdot 1$, rose 105 per cent. to reach $4 \cdot 3$. Hull, however, with the high decade rate of 3.0 per 1000, proved one of the exceptions to this rule, as its rate rose last autumn to 8.4 , or 180 per cent. The question naturally arises, Had the cheapness of fruit anything to do with this increase? Hull largely imports and Leeds largely consumes fruit. Has the habitually high diarrhœa-rate in Leeds, increased last year by 50 per cent., and has the habitually high rate at Hull, increased last year by 180 per cent.. anything, or any great thing, to do with fruit? Speaking offhand, one is inclined to answer "No." The mortality from diarrhoea, as every medical man knows, is chiefly amongst young infants, who do not generally get much fruit. Still, it might be answered that if they do not

A paper real before the Yorkshire Branch of the British Medical Association, at Leeds, May 30th, 1804 . 